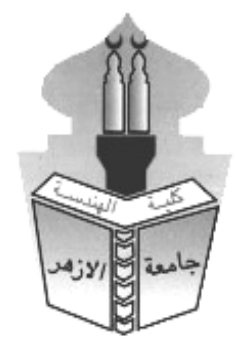

\title{
EPERIMENTAL INVESTIGATION OF THERMAL AND PRESSURE DROP PERFORMANCE OF CROSS- FLOW WIRE MESH HEAT EXCHANGERS
}

\author{
M. A. Sayed*, A. M. T. A. ELdein Hussin, W. Aboelsoud and N. A. Mahmoud \\ Mechanical Power Engineering Department, Faculty of Engineering, Ain Shams University, \\ Cairo, Egypt. \\ *Corresponding Author E-mail: mohamedasayed00@gmail.com
}

\begin{abstract}
For the purpose of enhancing the heat transfer performance of cross-flow heat exchangers, extended surfaces are attached on the gas side, thus increasing the surface area and lowering the convection heat transfer resistance. Experiments have been carried out to evaluate the performance of four modules of cross flow heat exchangers. All heat exchanger modules have ten equally-spaced copper tubes in vertical alignment.A sheet of copper woven wire mesh was corrugated in the form of rectangular-shape. Then, it was press-fitted to the tube to form a wire mesh heat exchanger. One module has bare copper tubes. The other three wire mesh heat exchanger modules were manufactured with 2,3 , and $4 \mathrm{~mm}$ wire mesh layer-to-layer spacings for comparison purposes. Copper tubes containing hot distilled water flow of the heat exchanger modules, were subjected to external air flow forced convection heat transfer into an air duct having a $20 \mathrm{~cm} \times 20 \mathrm{~cm}$ cross sectional inside area. The pressure drop in the air stream and the temperature of the hot water inlet and outlet were recorded. The significance of this experimental work is the use of a low cost and commercially available woven wire mesh sheet as extended heat transfer surface. A comparison was made between the results of this study and results of other enhanced cross-flow heat exchangers, obtained from open literature. Results showed an enhancement of the Nusselt number for all the wire mesh finned modules as compared to that of the bare module. Volumetric heat transfer coefficient results showed, an average increase of $113.9 \%, 91.5 \%$, and $81.4 \%$ in the 3,4 , and $2 \mathrm{~mm}$ wire mesh heat exchangers, respectively, as compared to the bare heat exchanger module.
\end{abstract}

KEYWORDS: Cross-Flow Heat Exchanger, Bare Pipes, Wire Mesh Heat Exchanger, Porous Structure, Nusselt Number. 


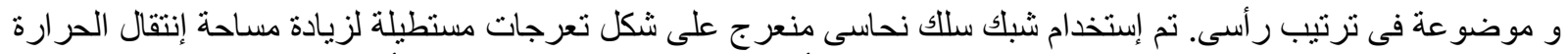

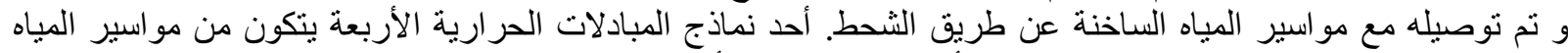

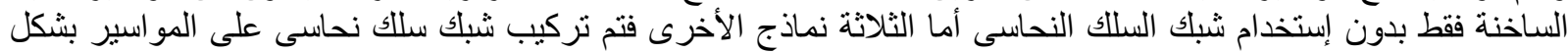

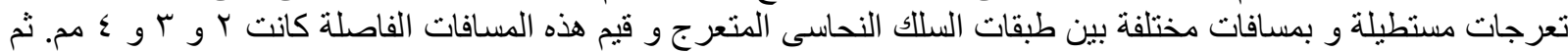

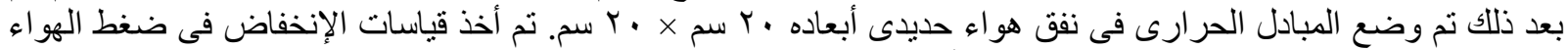

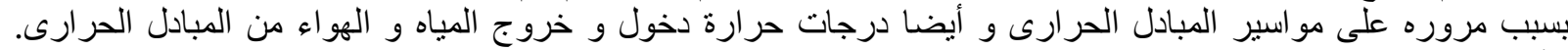

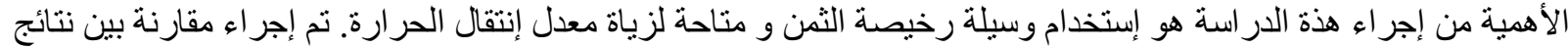

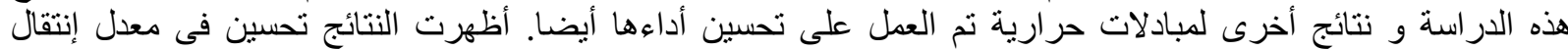

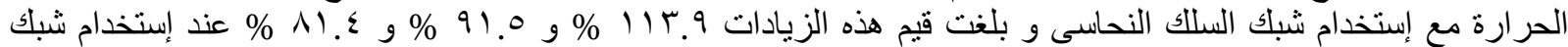

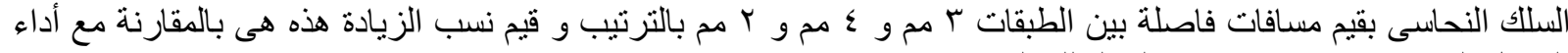

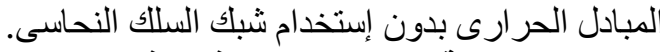

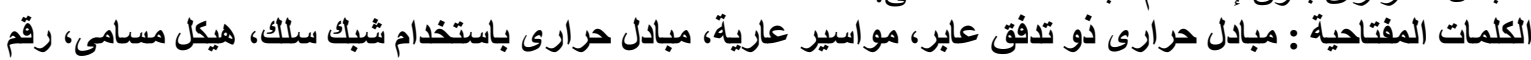
ناسلت : ن مبادل جرار

\begin{tabular}{|c|c|c|c|}
\hline \multicolumn{4}{|c|}{ Nomenclature } \\
\hline$\overline{A_{\text {in }}}$ & inside tube surface area $\left[\mathrm{m}^{2}\right]$ & $\begin{array}{l}\mathbf{V}_{\infty} \\
\text { (or } \\
\mathbf{U}_{\infty} \text { ) }\end{array}$ & $\begin{array}{l}\text { average air velocity in the free cross- } \\
\text { sectional area of the air duct }[\mathrm{m} / \mathrm{s}]\end{array}$ \\
\hline $\mathbf{A}_{\text {out }}$ & outer tube surface area $\left[\mathrm{m}^{2}\right]$ & V & volume flow rate $\left[\mathrm{m}^{3} / \mathrm{s}\right]$ \\
\hline $\mathbf{A U}$ & overall heat transfer conductance [W/K] & $\mathbf{X}_{\mathrm{T}}$ & transversal tube pitch $[\mathrm{m}]$ \\
\hline $\mathbf{C}_{\mathrm{p}}$ & specific heat at constant pressure [J/kg.K] & $\mathbf{X}_{\mathrm{t}}$ & wire mesh transversal pitch [mm] \\
\hline$d_{\text {out }}$ & tube outside diameter [m] & & overall efficiency \\
\hline & & \multicolumn{2}{|c|}{ Greek Symbols } \\
\hline $\mathbf{F}$ & correction factor & $\mathbf{v}$ & kinematic viscosity $\left[\mathrm{m}^{2} / \mathrm{s}\right]$ \\
\hline $\mathbf{h}_{\text {in }}$ & tube inside heat transfer coefficient $\left[\mathrm{W} / \mathrm{m}^{2} . \mathrm{K}\right]$ & $\mu$ & dynamic viscosity $\left[\mathrm{N} . \mathrm{s} / \mathrm{m}^{2}\right]$ \\
\hline $\mathbf{h}_{\mathbf{0}}$ & outer convection heat transfer coefficient $\left[\mathrm{W} / \mathrm{m}^{2} . \mathrm{K}\right]$ & $\rho$ & density $\left[\mathrm{kg} / \mathrm{m}^{3}\right]$ \\
\hline $\mathbf{h}_{\text {out }}$ & $\begin{array}{l}\text { outer air convection heat transfer coefficient, } \\
{\left[\mathrm{W} / \mathrm{m}^{2} . \mathrm{K}\right]}\end{array}$ & $\eta$ & efficiency \\
\hline $\mathbf{h}_{\mathbf{v}}$ & $\begin{array}{l}\text { volumetric convective heat transfer coefficient } \\
{\left[\mathrm{W} / \mathrm{m}^{3} \cdot \mathrm{K}\right]}\end{array}$ & \multicolumn{2}{|c|}{ Subscripts } \\
\hline $\mathbf{k}_{\text {air }}$ & thermal conductivity of air $[\mathrm{W} / \mathrm{m} . \mathrm{K}]$ & $\mathbf{a}$ & air \\
\hline $\mathbf{k}_{\text {Pipe }}$ & thermal conductivity of pipe material [W/m.K] & avg & average \\
\hline $\mathbf{l}_{\mathbf{P}}$ & copper pipe length $[\mathrm{m}]$ & $\mathbf{c}$ & Cross-section \\
\hline m & mass flow rate $[\mathrm{kg} / \mathrm{s}]$ & $\mathbf{d}$ & based on outer pipe diameter \\
\hline$\Delta \mathbf{P}$ & air pressure drop across heat exchanger module [Pa] & in & inlet \\
\hline PPi & pore per inch & out & outlet \\
\hline $\mathbf{P} / \mathbf{V}$ & $\begin{array}{l}\text { pumping power per unit volume of heat exchanger } \\
\text { module }\left(\mathrm{W} / \mathrm{m}^{3}\right)\end{array}$ & lam & laminar \\
\hline$Q$ & hot water heat transfer rate $[\mathrm{W}]$ & $\mathbf{p}$ & pipe \\
\hline $\mathbf{R e}_{\mathrm{d}, \infty}$ & $\begin{array}{l}\text { Reynold's number based on outer pipe diameter and } \\
\text { air velocity }\end{array}$ & tot & total \\
\hline $\mathbf{R}_{\text {tot }}$ & total heat transfer resistance $[\mathrm{K} / \mathrm{W}]$ & th & thermal \\
\hline & spacing between woven wire mesh sheet layers [mm] & turb & turbulent \\
\hline$\Delta \mathrm{T}_{\mathrm{LM}}$ & $\begin{array}{l}\text { logarithmic mean temperature } \\
\text { difference }\left[{ }^{\circ} \mathrm{C} \text { or } \mathrm{K}\right]\end{array}$ & $\mathbf{v}$ & volumetric \\
\hline $\mathbf{T}$ & temperature $\left[{ }^{\circ} \mathrm{C}\right]$ & $\mathbf{w}$ & water \\
\hline $\mathbf{U}$ & overall heat transfer coefficient $\left[\mathrm{W} / \mathrm{m}^{2} . \mathrm{K}\right]$ & & \\
\hline
\end{tabular}




\section{INTRODUCTION}

Many different applications involve heat exchange processes like heat exchangers, which are used in air conditioning, electrical components cooling, and waste heat recovery (Bejan \& Kraus, 2003; Rashidi, Kashefi, Kim, \& Samimi-Abianeh, 2019). Mostly, the heat exchanger involves convection heat transfer on one or both side of the fluids separating wall (Kakaç, Liu, \& Pramuanjaroenkij, 2002; Kraus, Aziz, Welty, \& Sekulic, 2001). Therefore, usually extended surfaces like fins, porous structures of different geometries are attached to the fluid side having the lower convective heat transfer coefficient (Kakaç et al., 2002; Kraus et al., 2001). The use of porous matrix like metal foams, and wire mesh is one of the most promising solution in that field. (Rashidi et al., 2019). Metal foams have been extensively investigated for their thermal and pressure drop characteristics in order to be used in different heat exchange applications. Chumpia and Hooman (Chumpia \& Hooman, 2014), and (Chumpia \& Hooman, 2015) experimentally examined the heat transfer and fluid flow friction of five circular tubes subjected to air cross flow. also performed a heat transfer and fluid friction experimental analysis of single row cross flow heat exchanger composed of three foam-covered tubes. T'Joen, et al. (T'Joen et al., 2010), experimentally evaluated the heat transfer and pressure drop performance of a single row waterto-air cross-flow heat exchanger, composed of foam-wrapped pipes. Sven De Schampheleire, et al. (De Schampheleire et al., 2013), compared the thermal performance of two similar, louveredfinned, and aluminium foam liquid-to-air cross flow heat exchangers. subjected to forced air convection cooling. subjected to forced air flow in a channel..

Wire meshes used as porous insert for thermal performance improvement are also investigated in many studies. Yanchen Fu et al. (Fu, Wen, \& Zhang, 2017), experimentally assessed the thermal characteristics of air-to-air cross-flow wire mesh heat exchanger. About $25.9 \%$ enhancement in the thermal performance was achieved. Rezaey et al. (Rezaey et al., 2014), evaluated experimentally the feasibility of using a stainless-steel wire mesh used as an extended surface welded to a water-cooled stainless steel U-shaped pipe for improving heat transfer performance. Dyga and Płaczek (Dyga \& Płaczek, 2010), conducted an experimental work to assess the fluid flow characteristics and heat transfer performance of cylindrical multi-layered wrapped wire mesh packing which was used as a heat transfer enhancing porous insert in internal flow. Kurian et al, (Kurian, Balaji, \& Venkateshan, 2016), compared experimentally the heat transfer and hydrodynamic performances of three different fabricated water to air heat exchangers. The three fabricated heat exchangers involved comparison of wire mesh, metal foam, as compared to the bare module performance. In this research work, a cross flow water-to-air wire mesh heat exchanger consisted of ten copper tubes, equally-spaced row, was tested under steady state conditions. Three modules having different layer-to-layer spacings of a wire mesh were tested and compared to a bare tube module. The experiments on the four heat exchanger modules were conducted for air cross flow average velocity range of 2.8 up to $14.9 \mathrm{~m} / \mathrm{s}$.

\section{EXPERIMENTAL TEST RIG AND PROCEDURE}

Four cross-flow, single-row heat exchanger modules were fabricated in this study. Three of them were wire mesh heat exchangers, and a fourth bare module was also manufactured and used as a benchmark. Each one of the four heat exchangers, was composed of ten equally-spaced copper tubes in a vertical alignment. The tube side fluid was hot distilled water which flowed inside the ten copper tubes in a parallel flow arrangement from an inlet header. The external cross-flowing shell side fluid was cool air drawn via a centrifugal blower from the ambient. All copper tubes had an identical length of $20 \mathrm{~cm}$, inner and outer diameters of 8.1 , and $9.5 \mathrm{~mm}$ respectively. The test section of each of the heat exchangers had the same dimensions as that of the air square duct cross-section of $20 \mathrm{~cm}$ x $20 \mathrm{~cm}$. A copper alloy (containing $40 \%$ copper) woven wire mesh of continuous sheet was made corrugated in the form of rectangular shape, and then press-fitted onto the heat exchanger pipes. For wire mesh heat exchangers, the tubes were attached with the corrugated wire mesh sheet by press-fitting bonding method. Both tested bare and wire mesh heat exchanger modules in this study are illustrated in Figure 1-a, and Figure 1-b. 


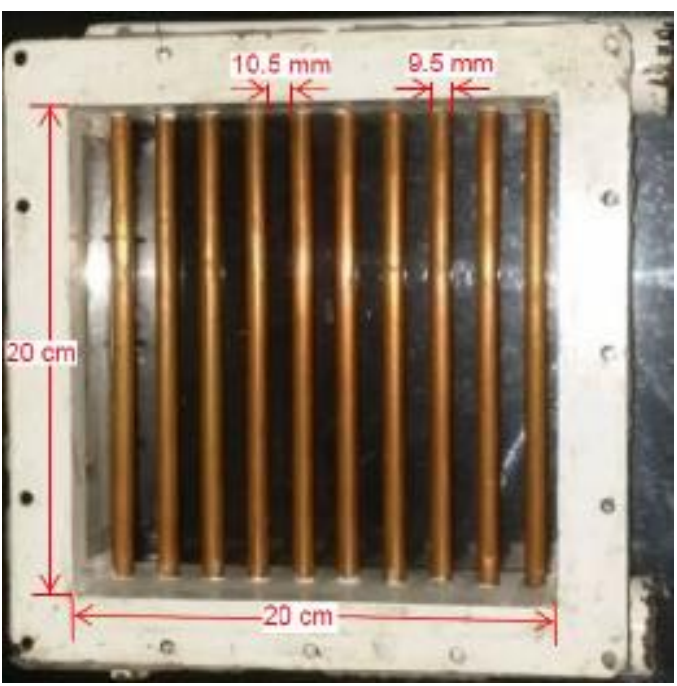

(a) Bare heat exchanger module

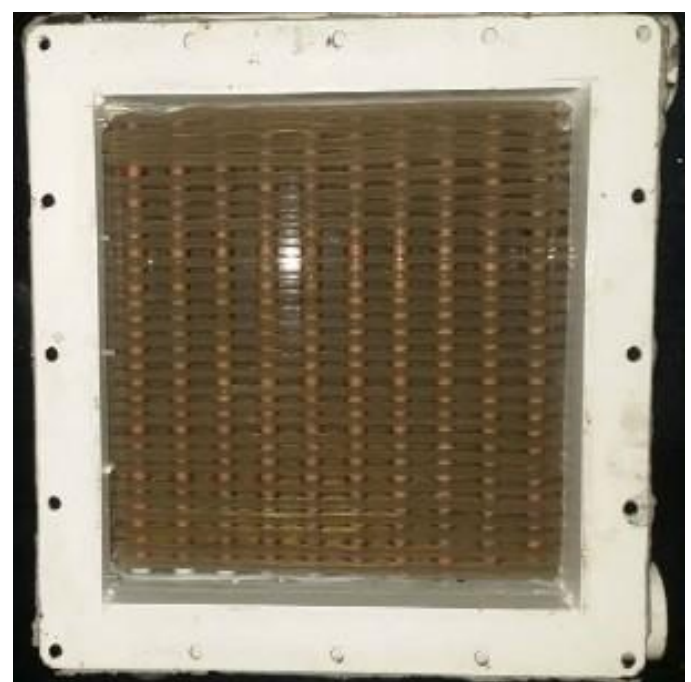

(b) Wire mesh heat exchanger module

Figure 1: Pictures of the different heat exchanger modules.

The woven wire mesh screens have a wire diameter of $0.15 \mathrm{~mm}$ with a square pore size of $0.3 \mathrm{~mm} \times 0.3 \mathrm{~mm}, 57 \mathrm{PPi}$, and a porosity value of $74 \%$. There were three values of the spacings between the layers of corrugated wire mesh of 2,3 , and $4 \mathrm{~mm}$. The dimensions of the employed woven wire mesh screen is illustrated via electronic microscope in figure 2.

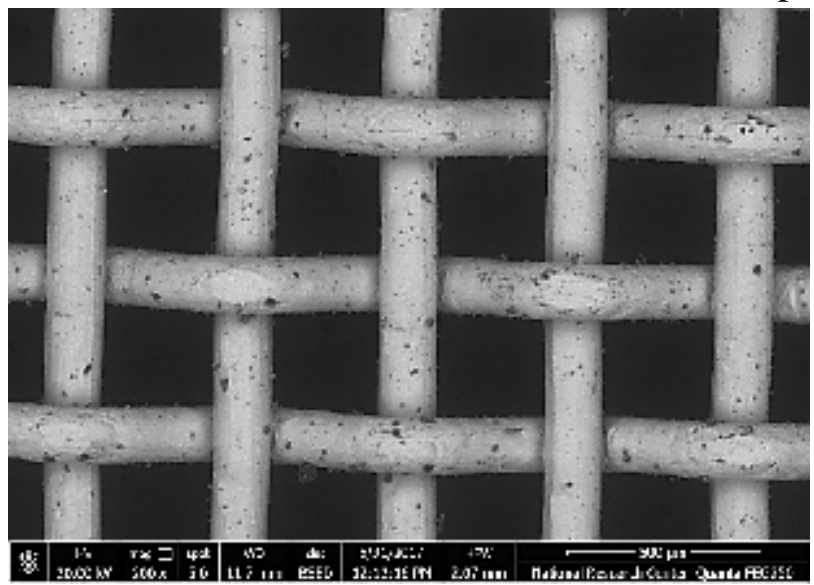

Figure 2: Microscopic view of the woven wire mesh fibers' size and pores.

The heat exchanger test rig is consisted of two fluid loops, one closed loop for hot distilled water circulation, and the other is an open-air tunnel loop for air flow across the heat exchanger tubes. Both water and air loops, in addition to the measuring devices used on each line are explained in detail in the following two sections.

\subsection{Hot circulated distilled water closed loop}

Hot distilled water was passed through the heat exchanger tubes to transfer heat to the external coolant air flow. Distilled water was heated in a stainless-steel tank via a 4-kW capacity heater. Heater's electrical power supply was controlled by an AC-voltage regulator to ensure constant inlet hot water temperature $( \pm 0.1 \mathrm{oC})$ to the heat exchanger module when varying either the air flow velocity or the water flow rate to the heat exchanger pipes. Then, the heated distilled water was pumped into the heat exchanger tubes from the water tank via a $0.75 \mathrm{hp}, 2$-phase centrifugal circulating pump (Calpeda-MXHM 204A). A by-pass line and two manually-controlled flow 
control valves were provided in order to control the flow rate to the heat exchanger, and the flow returned to the supply water tank. Then the water is passed through the heat exchanger tubes and from the tubes' outlet to a turbine flow meter (Gems FT-110 Series) having an uncertainty of \pm $0.01 \mathrm{~L} / \mathrm{min}$, that is used to measure the flow rate. Calibrated digital temperature panels having an uncertainty value of $\pm 0.1 \mathrm{oC}$, were used to measure the inlet and exit water temperatures. The hot distilled water closed loop is depicted in Figure 3.

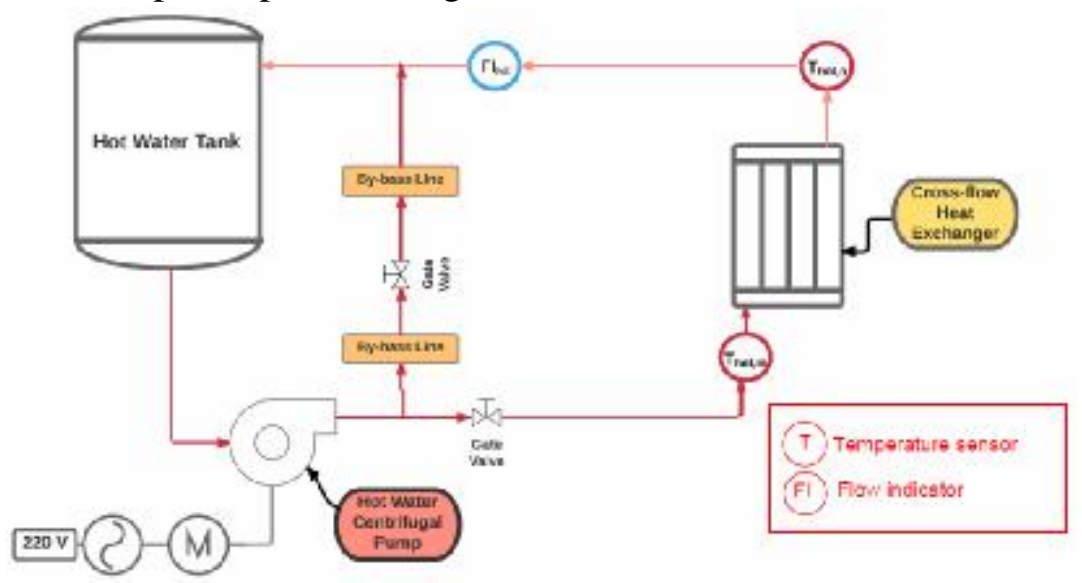

Figure 3: Hot distilled water closed loop.

\subsection{External air flow open circuit}

The heat exchanger test section was located downstream of the inlet section of an air duct at a distance about $2.3 \mathrm{~m}$ to ensure fully developed flow of air at inlet to the heat exchanger. Air enters the duct at room temperature via a $5.5 \mathrm{hp}, 3$-phase centrifugal blower (Y112M - 4) that was located at the end of the outlet section of air duct after the heat exchanger test section (suction side). The average air velocity and thus the volume flow rate is varied using air damper that was installed at the outlet of centrifugal blower.

The air centerline velocity at the inlet to heat exchanger was measured by a hot wire anemometer (Testo-425) having an uncertainty of $\pm 0.01 \mathrm{~m} / \mathrm{s}$. Then the average velocity was calculated from the corresponding measured centerline velocity. The pressure drop of the air flow across each heat exchanger module was measure using a U-tube manometer having water as the manometric fluid and uncertainty value of $\pm 1 \mathrm{~mm}$. Air inlet temperature at the centerline of air duct was measured by using a calibrated K-type thermocouple. Temperature of air at inlet to the heat exchanger was measured with a calibrated K-type thermocouple. Outlet air temperature was calculated from applying the heat balance equation on the heat exchanger between the two exchanging fluids. Corrugated wire mesh screens were attached to the one row heat exchanger modules by pressfitting. Air duct was insulated during experiments using a $5 \mathrm{~cm}$-thick, glass wool sheet to minimize the heat losses to the ambient. The air tunnel open circuit loop is shown in figure 4. 


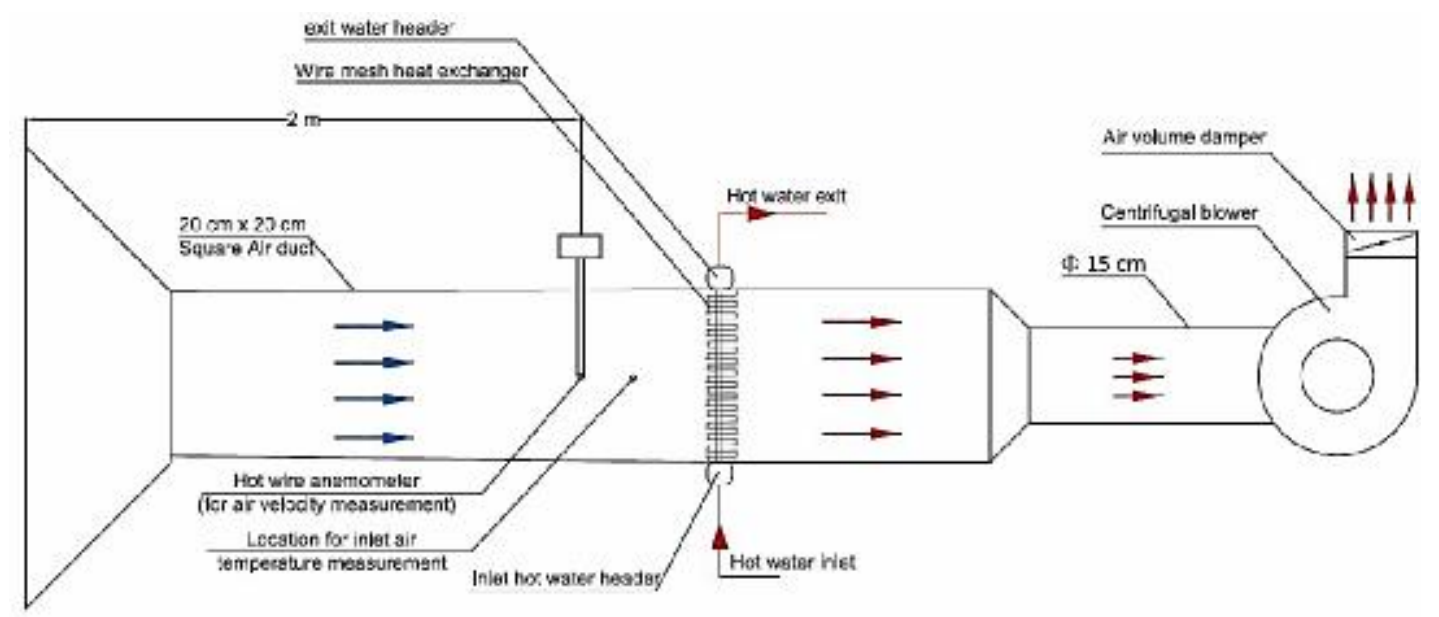

Figure 4: External open loop for air flow across heat exchanger sample.

\subsection{Experimental procedure}

Steady state forced convection heat transfer experiments were conducted for each module of the heat exchangers at different air velocities, water flow rates, and hot water inlet temperatures to each heat exchanger. The procedure of the experiments involved starting the centrifugal blower, water heater, and hot water circulating pump. Air flow rate was adjusted by varying the opening of the volume air damper installed at the exit of the centrifugal blower. At each air volume damper opening, the water inlet temperature was adjusted using the AC-voltage regulator to maintain a preset temperature value. When steady state conditions were reached, inlet and outlet air temperatures, entering and exit water temperatures, air velocity, hot water flow rate, and the pressure drop measurements were all taken. Steady state conditions were considered to be reached when the measured temperature values were varied within only $\pm 0.1 \mathrm{oC}$. All of these measurements were taken for three different water flow rates of 5,7 , and $9 \mathrm{~L} / \mathrm{min}$ and also at varying inlet hot water temperatures to the heat exchanger having values of $60 \mathrm{oC}, 70 \mathrm{oC}$, and 80oC. All experiments were conducted for the four heat exchanger modules at varying average air velocity range between 2.8 and $14.9 \mathrm{~m} / \mathrm{s}$.

\section{RESULTS AND DISCUSSION}

\subsection{Heat transfer analysis}

Steady state heat transfer tests were carried out for the four heat exchanger modules at the same experimental conditions for comparison purposes. For each of the heat exchangers the air flow velocity varied between 2.8 and $14.9 \mathrm{~m} / \mathrm{s}$. This velocity range involves broad range of turbulent flow conditions.

Logarithmic mean temperature difference thermal analysis method was adopted in this research work to estimate the performance of each of the heat exchangers and by use of the heat transfer rate calculated from the hot water side by applying the energy equation (1),(Bergman, Incropera, DeWitt, \& Lavine, 2011; Kakaç et al., 2002).

$$
\dot{\mathrm{Q}}_{\mathrm{w}}=\dot{\mathrm{m}}_{\mathrm{w}} * \mathrm{c}_{\mathrm{p}, \mathrm{w}} *\left(\mathrm{~T}_{\mathrm{w}, \mathrm{in}}-\mathrm{T}_{\mathrm{w}, \text { out }}\right)
$$

Logarithmic mean temperature difference can then be calculated using equation (2), (Bejan \& Kraus, 2003; Bergman et al., 2011; Kakaç et al., 2002; Schlunder, 1983). 


$$
\Delta \mathrm{T}_{\mathrm{LM}}=\frac{\left(\mathrm{T}_{\mathrm{win}}-\mathrm{T}_{\mathrm{s}_{\text {out }}}\right)-\left(\mathrm{T}_{\mathrm{w}, \text { aut }}-\mathrm{T}_{\mathrm{a}, \mathrm{in}}\right)}{\ln \left(\frac{\mathrm{T}_{\mathrm{w} \text {,in }}-\mathrm{T}_{\mathrm{a,aut}}}{\mathrm{T}_{\mathrm{w} \text { out }}-\mathrm{T}_{\mathrm{a} \text {,in }}}\right)}
$$

Then the overall heat transfer conductance (AU) could be estimated from equation (3), (Bejan \& Kraus, 2003; Bergman et al., 2011; Kakaç et al., 2002).

$$
\dot{\mathrm{Q}}_{\mathrm{w}}=\mathrm{F} \cdot \mathrm{A} \cdot \mathrm{U} \cdot \Delta \mathrm{T}_{\mathrm{LM}}
$$

where $(\mathrm{F})$ is a correction factor related to the crossflow heat exchanger type. However, since the calculated value of correction factor, $\mathrm{F}$ was so close to unity in most cases of this study, it was taken as one in all thermal calculations. Also, the unit value of factor, $F$ that relies on the heat exchanger type and inlet exit temperatures of water, was adopted in thermal analysis calculations. The total heat transfer resistance can then be determined from equation (4).

$$
R_{\text {tot }}=\frac{1}{A U}=\frac{1}{h_{\text {in }} A_{\text {in }}}+\frac{\ln \left(\frac{d_{\text {out }}}{d_{\text {in }}}\right)}{2 \pi k_{\text {pipe }} l_{p}}+\frac{1}{h_{\text {out }} A_{\text {out }} n_{\text {o }}}
$$

Equation (4) can be rearranged and used for the computation of the outer convective heat transfer coefficient as shown in equation (5).

$$
\frac{1}{h_{\text {out }} A_{\text {out }}}=\frac{1}{A U}-\frac{1}{h_{\text {in }} A_{\text {in }}}-\frac{\ln \left(\frac{d_{\text {out }}}{d_{\text {in }}}\right)}{2 \pi k_{\text {pipe }} l_{p}}
$$

where no, overall efficiency, is considered as one, since its value is usually very close to unity as adopted in Chumpia and Hooman (Chumpia \& Hooman, 2015). The internal convection heat transfer coefficient on the water side hin could be calculated from Gnielinski formula (Gnielinski, 1976), having an uncertainty value of $10 \%$. The third term on the right-hand side of equation (5) is the conduction heat transfer resistance of the copper pipe wall having inner and outer diameters of 8.1 and $9.5 \mathrm{~mm}$ respectively. The thermal conductivity of copper used in conduction resistance calculation is taken as $380 \mathrm{~W} / \mathrm{m} . \mathrm{K}$ (Holman, 1998), and the pipe length is $20 \mathrm{~cm}$. The external convection heat transfer coefficient is calculated based on the copper tube outer surface area (Ao) which is identical for all of the heat exchanger modules.

Reynold's number based on the outer pipe diameter and average air velocity, is defined as presented in equation (6).

$$
\operatorname{Re}_{\mathrm{d}, \infty}=\frac{\rho_{\text {air }} \cdot \mathrm{d}_{\text {out }} \cdot V_{\infty}}{\mu_{\text {sir }}}
$$

Figure 5, and figure 6, show the variation of hot water temperature drop with average air velocity for the four heat exchanger modules. Water temperature drop increases with the increase in average air velocity (Fu et al., 2017). This is due to the higher turbulence at greater air velocities which enhances more active convection heat transfer. It is obvious that water temperature drop in all wire mesh heat exchangers is larger than that in the bare heat exchanger. This illustrates the higher cooling effect achieved when wire mesh is attached to the heat exchangers. Figure 5, shows the change of water temperature drop with average air velocity for the bare and wire mesh heat exchangers, all for a fixed water inlet temperature of $80^{\circ} \mathrm{C}$, but at varying hot water flow rates of 5,7 , and $9 \mathrm{~L} / \mathrm{min}$. It is observed from figure 5 , that for all of the tested heat exchangers, as the water flow rate decreases, the water temperature drop increases. 


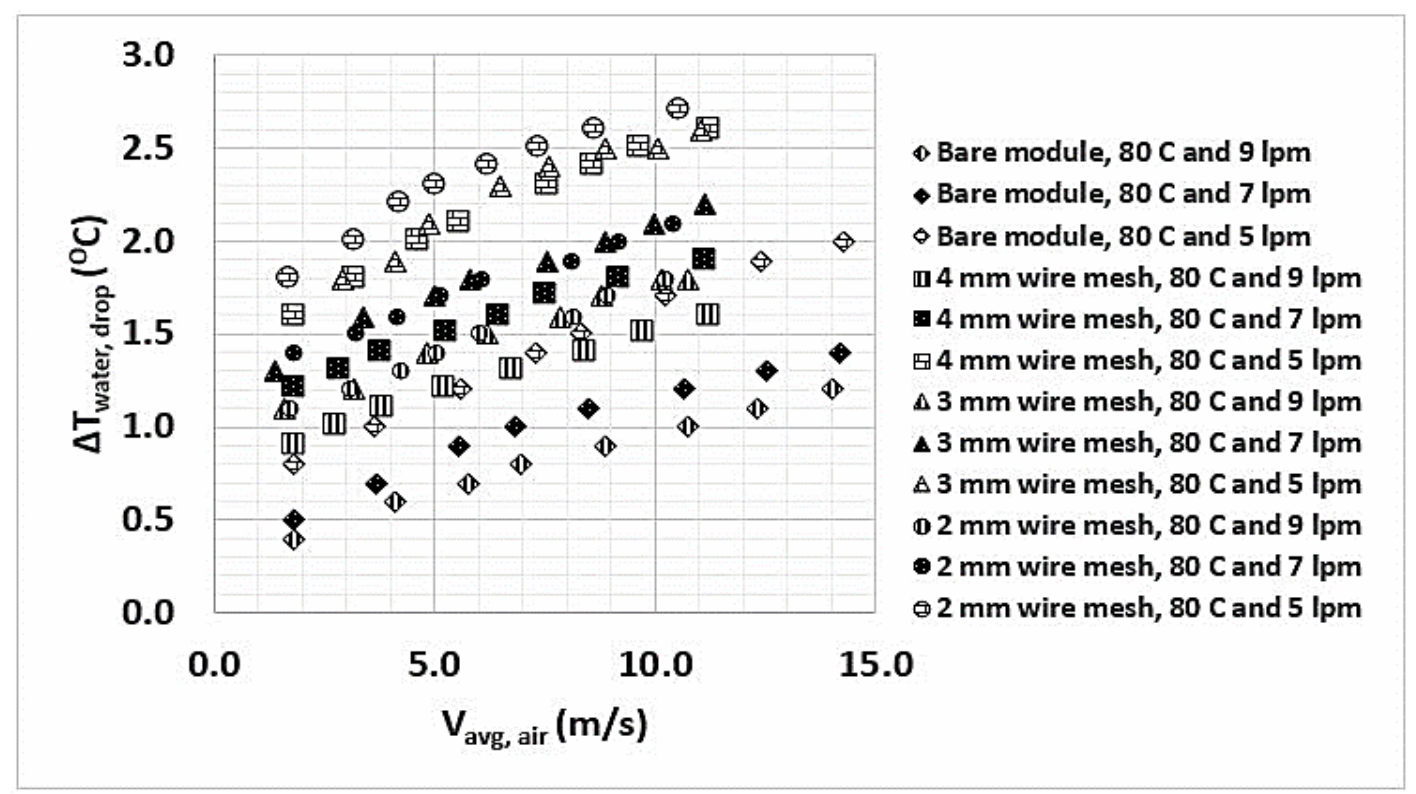

Figure 5: Variation of water temperature drop with average air velocity at same inlet water temperature of $80^{\circ} \mathrm{C}$, but various flow rates.

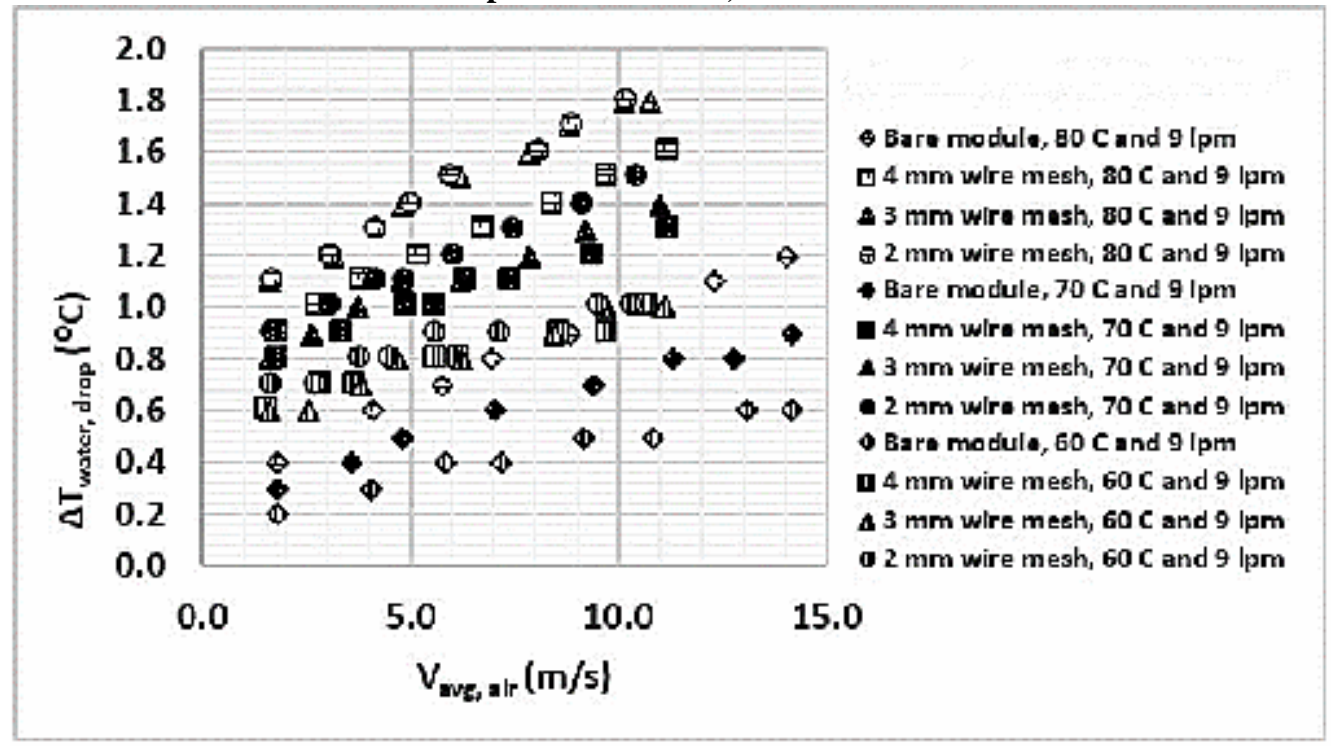

Figure 6: Variation of water temperature drop with average air velocity at same inlet water flow rate of $9 \mathrm{~L} / \mathrm{min}$, but various inlet temperatures.

This is as expected, because of the larger time of contact available between the hot and cold fluids at the lower low rates. The highest cooling effect is achieved with the $2 \mathrm{~mm}$ wire mesh heat exchanger due to its largest heat transfer surface area. Figure 6 shows the variation of water temperature drop with average air velocity of all heat exchangers at a fixed water flow rate of 9 $\mathrm{L} / \mathrm{min}$, but for different hot water inlet temperature values of $60 \mathrm{o}, 70 \mathrm{o}$, and $80 \mathrm{oC}$. It is obvious that the water temperature drop increases with the increase in inlet water temperature. This agrees well with the experimental data obtained of water heating in a wire mesh heat exchanger used for waste heat recovery that was tested in (Rezaey et al., 2014). All wire mesh heat exchangers cause temperature drop value higher than that for the bare module. 
The effect of varying the average air velocity on the amount of heat transfer rate from hot water is illustrated for the four heat exchanger modules in Figure 8-A, through Figure 8-D. It can be shown for all heat exchanger modules that the heat transfer rate increases pursuing the increase in average air velocity (Dyga \& Płaczek, 2010). All wire mesh heat exchangers achieve higher heat transfer rates as compared to the bare hear exchanger module though the entire velocity range. In addition, it is clear that there is no a peak value for the heat transfer rate over the investigated air velocity range, which reflects that the amount of heat rate is more influenced by the air mass flow rate than the rise in temperature.

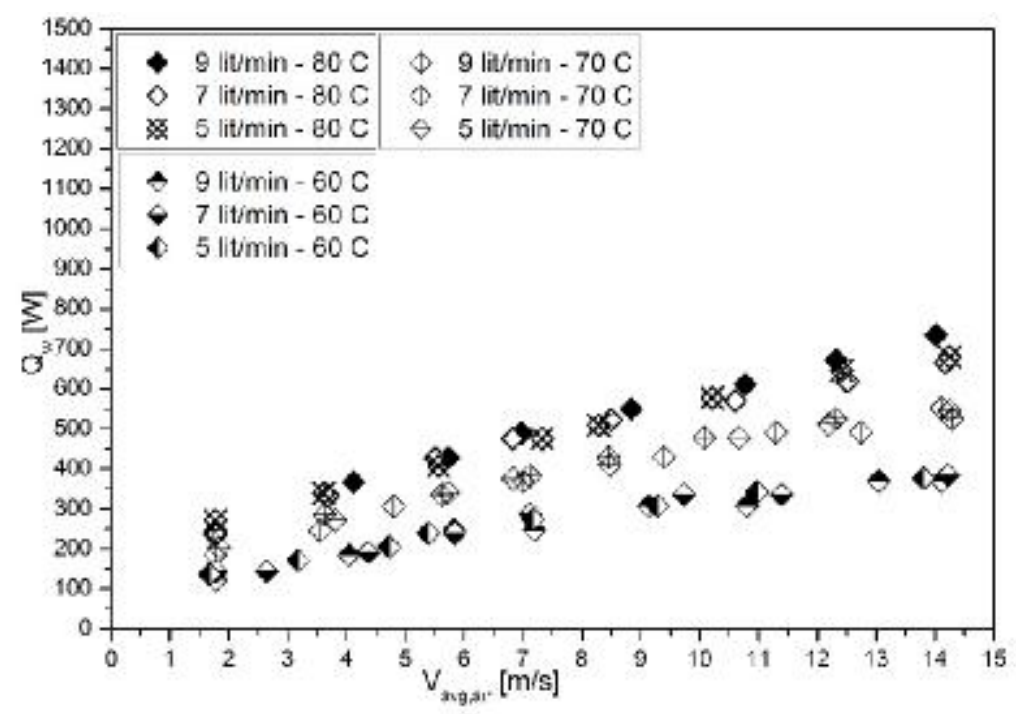

(A) Bare module.

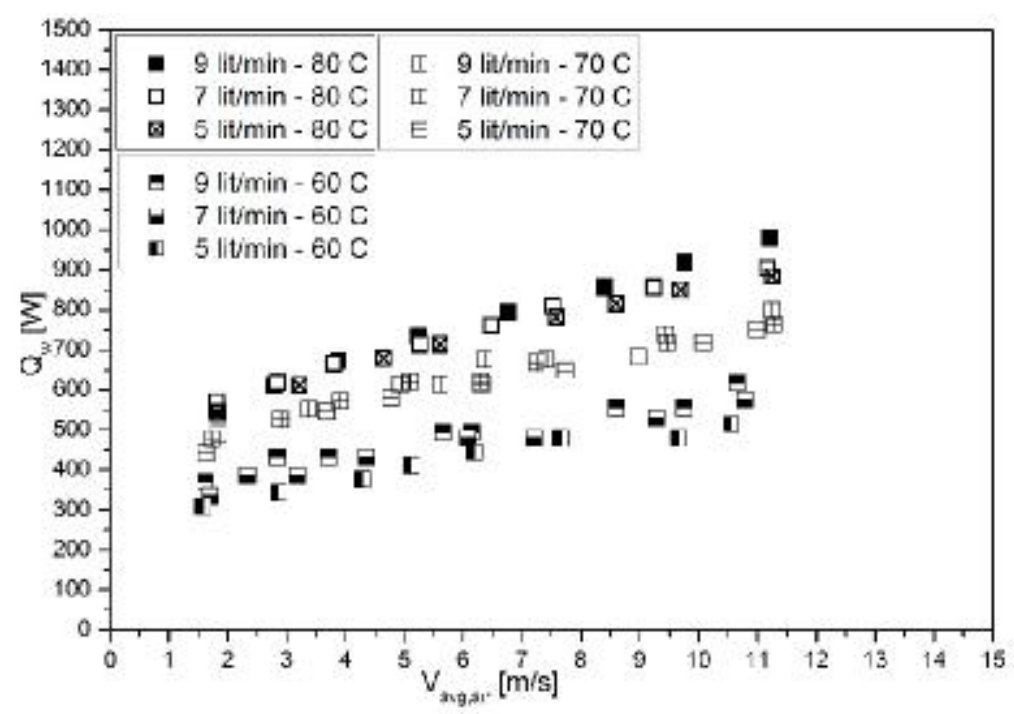

(B) $4 \mathrm{~mm}$, wire mesh heat exchanger.

Figure 7: Variation of heat transfer rate with average air velocity for different heat exchangers. 


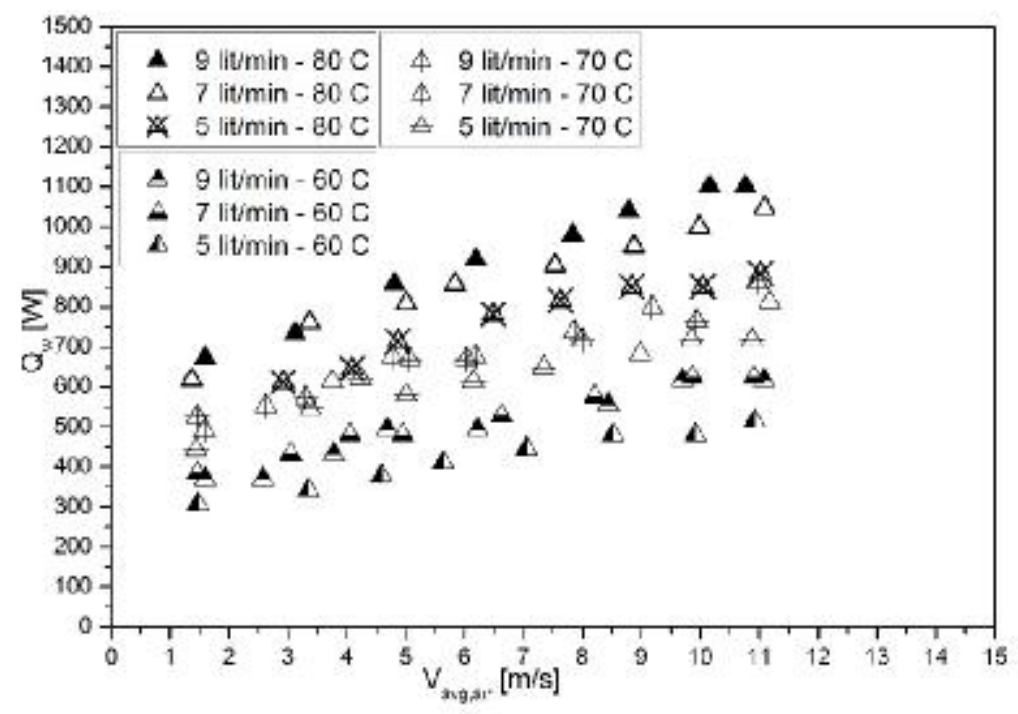

(C)3mm, wire mesh heat exchanger

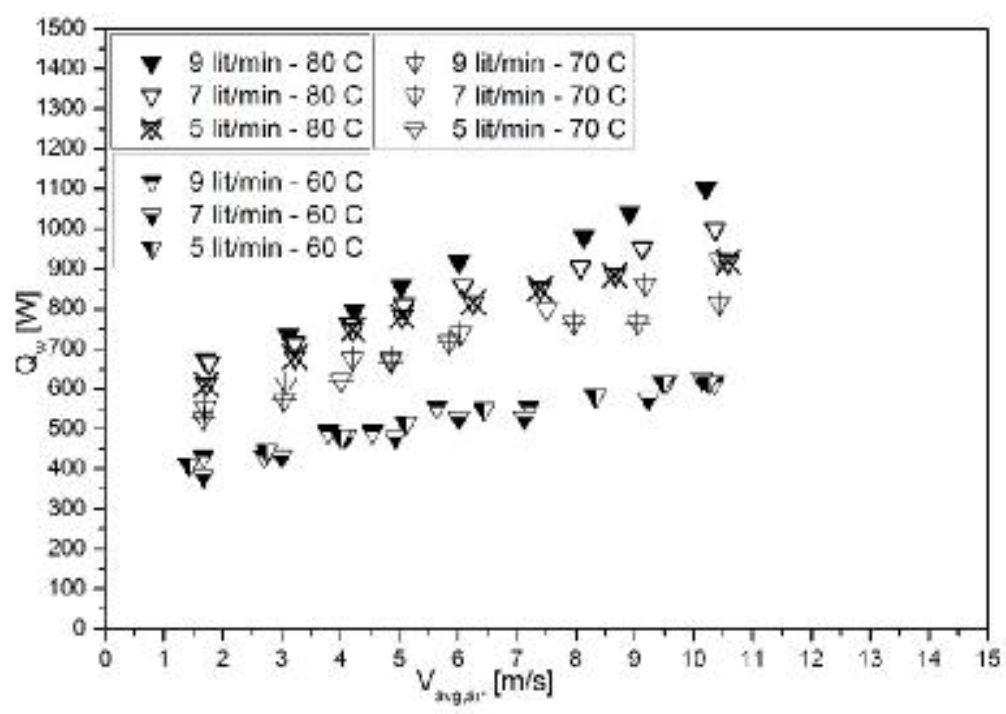

(D) $2 \mathrm{~mm}$, wire mesh heat exchanger

Figure 8: Variation of heat transfer rate with average air velocity for different heat exchangers.

Figure 8-A through Figure 8-D, also shows that the heat transfer rate increases when increasing both the inlet water temperature and the water flow rate. However, the effect of varying the water flow rate on the amount of heat transfer rate is not significant as illustrated.

Variation of thermal total resistance of the four heat exchangers is shown in

Figure 9. It is observed that all wire mesh heat exchangers have lower thermal resistance values than that for the bare heat exchanger. Thermal resistance also decreases with the increase in air velocity for performance evaluation of the cross-flow heat exchangers investigated in (Chumpia \& Hooman, 
2014, 2015; De Schampheleire et al., 2013; T'Joen et al., 2010). It is also seen that the lower wire mesh spacing is more efficient in transferring heat. The lowest thermal resistance values are that for the $2 \mathrm{~mm}$ wire mesh heat exchanger. A very close thermal performance is observed among all the wire mesh heat exchangers, due to the small difference in wire mesh spacings values. Total thermal resistance of all heat exchangers constantly decreases with the increase in average air velocity.

This is because the total thermal resistance if inversely proportional to the overall heat transfer coefficient which continuously increases with the increase in average air velocity, as a result of higher heat rate achieved at greater air velocities.

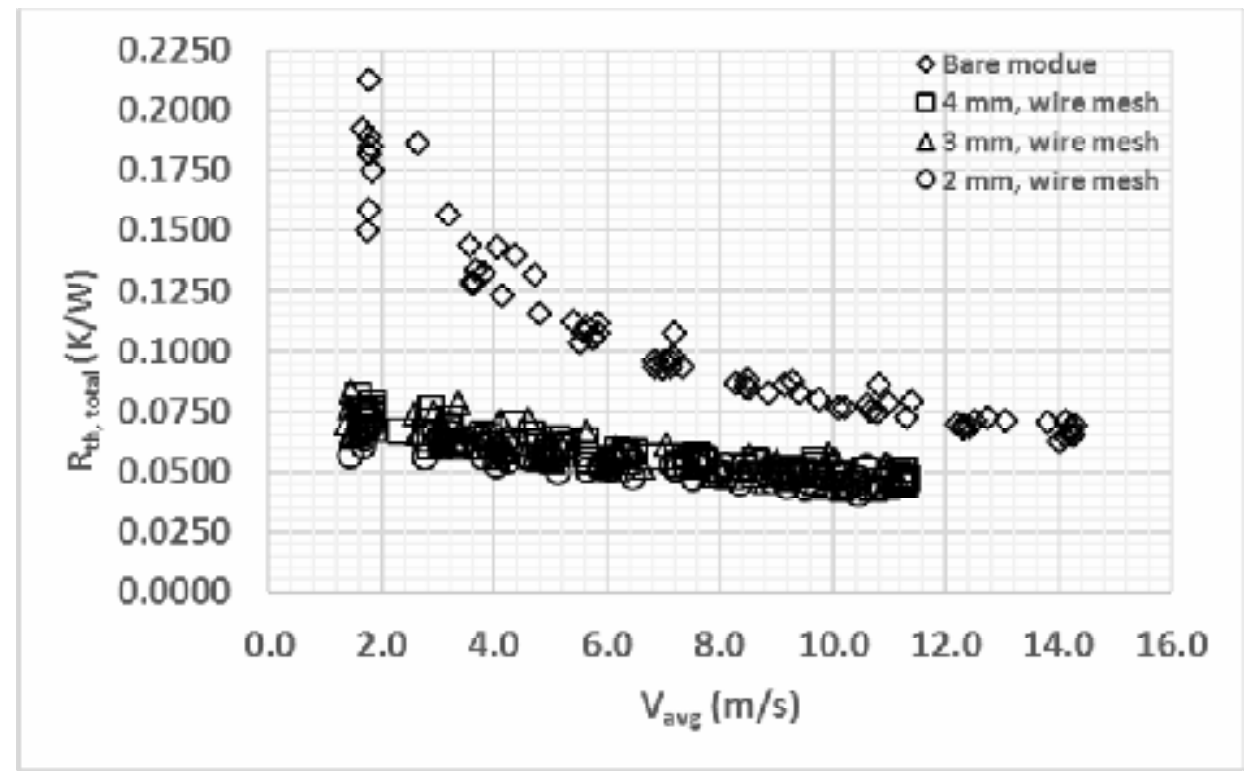

Figure 9: Variation of total thermal resistance with average air velocity.

\subsection{Pressure drop performance}

Figure 10 shows the variation of pressure drop of air across the different heat exchanger modules with varying the average air velocity. It can be shown from figure (9), that the pressure drop for all heat exchanger modules including the bare one, varies quadratically with air volume flow rate as depicted in (Chumpia \& Hooman, 2014; Kurian et al., 2016). All wire mesh heat exchangers exhibit larger air pressure drop than that for the bare module. Pressure drop also increases with the decrease in layer-to-layer spacing value. It was also observed, that for the $3 \mathrm{~mm}$, and $4 \mathrm{~mm}$ spaced finned heat exchanger modules, there was a very slight difference in pressure drop values. A maximum pressure drop value was measured for the $2 \mathrm{~mm}$ spaced, having a value of about 598 $\mathrm{Pa}$ at a maximum air velocity of $10.5 \mathrm{~m} / \mathrm{s}$. 


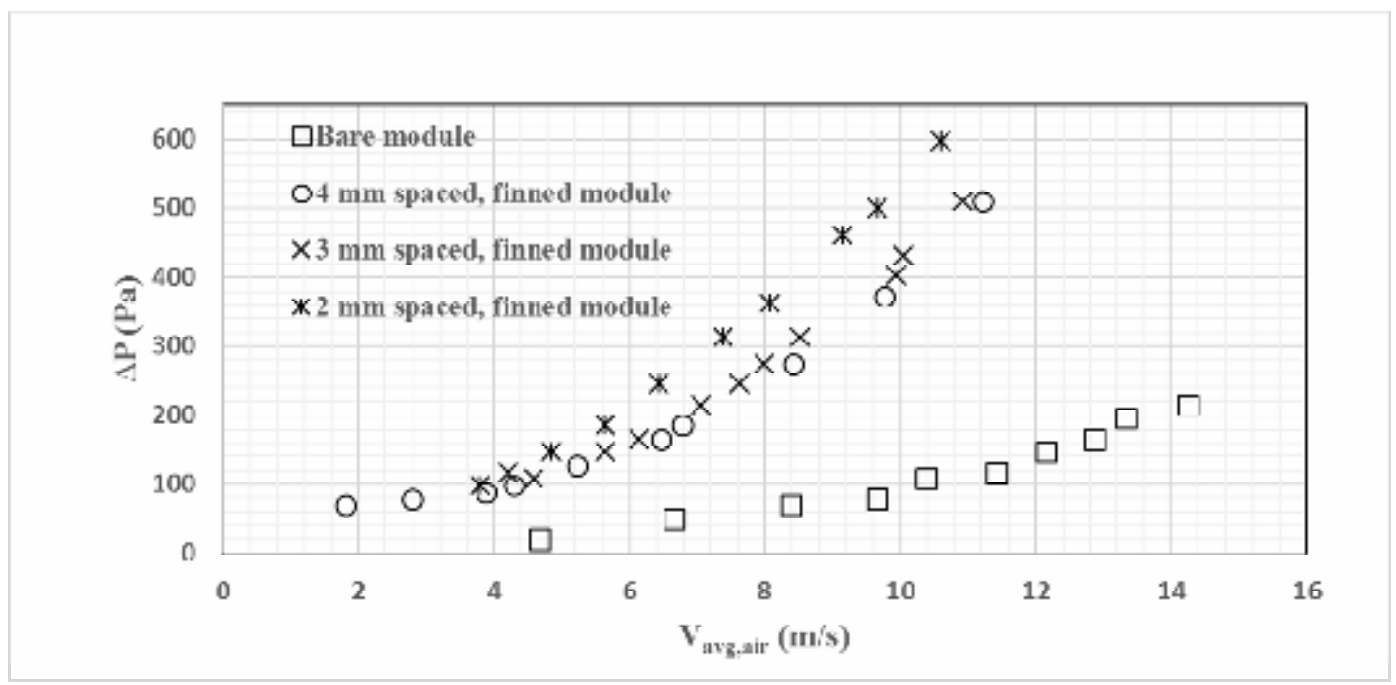

Figure 10: Pressure drop variation with air volume flow rate across the four tested heat exchanger module.

\section{COMBINED PERFORMANCE}

The variation of the ratio of heat transfer rate per unit pumping power with Reynold's number is depicted in Figure 11. As expected, as the flow rate increases, the pumping power required also increases. This is in a good agreement with the experimental data obtained for the internal air flow heating through a porous inserts investigated in (Garrity, Klausner, \& Mei, 2010; Venugopal, Balaji, \& Venkateshan, 2010). It is obvious that at a certain flow rate, the $3 \mathrm{~mm}$ wire mesh heat exchanger is more effective in transferring heat than that for the other wire mesh modules for the same pumping power. The $2 \mathrm{~mm}$ wire mesh heat exchanger exhibits the lowest ratio values due to the higher air pressure drop associated with this module. The pumping power is calculated as depicted in equation (7),

$$
\text { Pumping power }=\Delta \mathrm{P} * \dot{\mathrm{V}}_{\mathrm{air}}
$$

Where, $\dot{V}_{\text {air }}$, air volume flow rate, is estimated from average air velocity as shown in equation (8).

$$
\dot{V}_{\text {air }}=V_{\text {avg air }} * A_{c}
$$




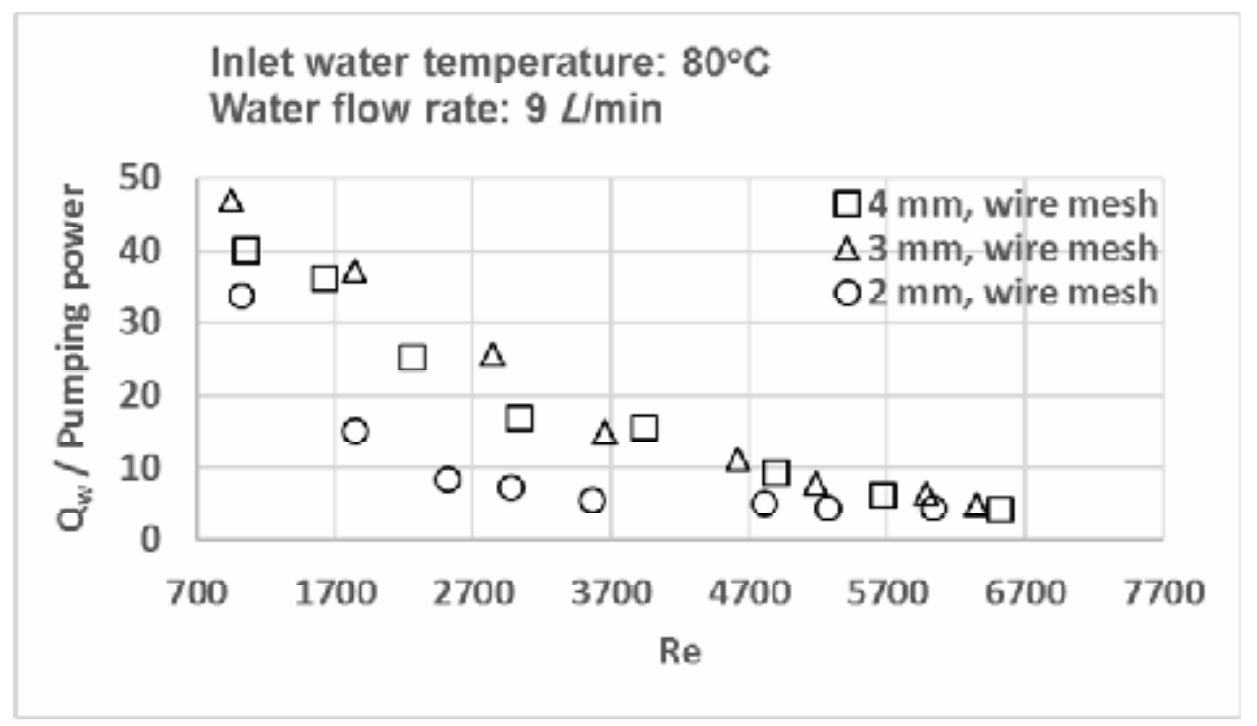

Figure 11: Heat transfer per pumping power versus Reynold's number.

\section{UNCERTAINTY ANALYSIS}

The uncertainty values of the measured parameters are listed in Table 1 . The error propagation in calculated results, because of the uncertainty of measured variables was estimated using the correlations presented in Moffat (Moffat, 1988), equation (9).

$$
\delta \mathrm{R}=\left\{\sum_{\mathrm{i}=1}^{\mathrm{N}}\left(\frac{\partial \mathrm{R}}{\partial \mathrm{X}_{\mathrm{i}}} . \delta \mathrm{X}_{\mathrm{i}}\right)^{2}\right\}^{1 / 2}
$$

where $R$ represents any primary measured physical parameter, and $\delta R$ is its uncertainty value. Using uncertainty calculation, the resulted uncertainty values in calculated results are evaluated and presented in Table 2.

Table 1: Uncertainty values of measured variables

\begin{tabular}{|l|c|}
\hline \multicolumn{1}{|c|}{ Quantity } & Uncertainty \\
\hline Temperature & $\pm 0.1^{\circ} \mathrm{C}$ \\
\hline Pressure head loss & $\pm 1 \mathrm{~mm}$ \\
\hline Velocity & $\pm 0.01 \mathrm{~m} / \mathrm{s}$ \\
\hline Water flow rate & $\pm 0.01 \mathrm{~L} / \mathrm{min}$ \\
\hline
\end{tabular}

Table 2: Maximum relative uncertainty values of physical calculated parameters

\begin{tabular}{|c|c|}
\hline Physical parameter & Uncertainty \\
\hline$\dot{m}_{w}$ & $0.11 \%$ \\
\hline$\dot{Q}_{w}$ & $11.8 \%$ \\
\hline$\Delta \mathrm{T}_{\mathrm{LM}}$ & $0.9 \%$ \\
\hline $\mathrm{h}_{\mathrm{O}}$ & $13.3 \%$ \\
\hline
\end{tabular}




\section{CONCLUSIONS}

Three modules of wire mesh heat exchangers were manufactured, each having a layer-to-layer spacing value different from the others, and a fourth bare heat exchanger module was also manufactured. Steady state forced convection experiments were conducted and conclusion are obtained as following:

- Wire mesh heat exchangers are promising choises for enhancing heat transfer rate at lower cost, simpler manufacturing.

- Wire mesh heat exchangers exhibit higher cooling effect in terms of water temperature drop, and heat transfer rate than that for the bare module. Water temperature drop increases with the decrease in water flow rate and at higher inlet water temperatures. Water temperature drop is around 1.75 times that in the bare heat exchanger.

- Pressure drop measurements reveal that, all wire mesh heat exchanger modules have higher pressure drop values than the bare heat exchanger. A maximum pressure drop value is measured for the $2 \mathrm{~mm}$ spaced, having a value of about $598 \mathrm{~Pa}$ at a maximum air velocity of $10.5 \mathrm{~m} / \mathrm{s}$.

- It was found that the $3 \mathrm{~mm}$ layer-to-layer spaced wire mesh heat exchanger has the highest heat transfer rate per pumping power at a specific Reynold's number among other wire mesh heat exchanger samples.

\section{REFERENCES}

1. Bejan, A., \& Kraus, A. D. (2003). Heat transfer handbook (Vol. 1): John Wiley \& Sons.

2. Bergman, T. L., Incropera, F. P., DeWitt, D. P., \& Lavine, A. S. (2011). Fundamentals of heat and mass transfer: John Wiley \& Sons.

3. Chumpia, A., \& Hooman, K. (2014). Performance evaluation of single tubular aluminium foam heat exchangers. Applied Thermal Engineering, 66(1-2), 266-273.

4. Chumpia, A., \& Hooman, K. (2015). Performance evaluation of tubular aluminum foam heat exchangers in single row arrays. Applied Thermal Engineering, 83, 121-130.

5. De Schampheleire, S., De Jaeger, P., Huisseune, H., Ameel, B., T'Joen, C., De Kerpel, K., \& De Paepe, M. (2013). Thermal hydraulic performance of 10 PPI aluminium foam as alternative for louvered fins in an HVAC heat exchanger. Applied Thermal Engineering, 51(1-2), 371-382.

6. Dyga, R., \& Płaczek, M. (2010). Efficiency of heat transfer in heat exchangers with wire mesh packing (Vol. 53).

7. Fu, Y., Wen, J., \& Zhang, C. (2017). An experimental investigation on heat transfer enhancement of sprayed wire-mesh heat exchangers. International Journal of Heat and Mass Transfer, 112, 699-708.

8. Garrity, P. T., Klausner, J. F., \& Mei, R. (2010). Performance of aluminum and carbon foams for air side heat transfer augmentation. Journal of heat transfer, 132(12), 121901.

9. Gnielinski, V. (1976). New equations for heat and mass transfer in turbulent pipe and channel flow. Int. Chem. Eng., 16(2), 359-368.

10. Holman, J. (1998). Heat transfer, 1997. P rocess E fficiency, Vol. 20, 40-60.

11. Kakaç, S., Liu, H., \& Pramuanjaroenkij, A. (2002). Heat exchangers: selection, rating, and thermal design: CRC press.

12. Kraus, A., Aziz, A., Welty, J., \& Sekulic, D. (2001). Extended surface heat transfer. In: American Society of Mechanical Engineers Digital Collection.

13. Kurian, R., Balaji, C., \& Venkateshan, S. (2016). Experimental investigation of near compact wire mesh heat exchangers. Applied Thermal Engineering, 108, 1158-1167.

14. Moffat, R. J. (1988). Describing the uncertainties in experimental results. Experimental Thermal and Fluid Science, 1(1), 3-17.

15. Rashidi, S., Kashefi, M. H., Kim, K. C., \& Samimi-Abianeh, O. (2019). Potentials of porous materials for energy management in heat exchangers-A comprehensive review. Applied energy, 243, 206-232. 
16. Rezaey, R., Salavati, S., Pershin, L., Coyle, T., Chandra, S., \& Mostaghimi, J. (2014). Fabrication of wire mesh heat exchangers for waste heat recovery using wire-arc spraying. Journal of thermal spray technology, 23(4), 609-615.

17. Schlunder, E. U. (1983). Heat Exchanger Design Handbook: Taylor \& Francis Inc.

18. T'Joen, C., De Jaeger, P., Huisseune, H., Van Herzeele, S., Vorst, N., \& De Paepe, M. (2010). Thermo-hydraulic study of a single row heat exchanger consisting of metal foam covered round tubes. International Journal of Heat and Mass Transfer, 53(15-16), 3262-3274.

19. Venugopal, G., Balaji, C., \& Venkateshan, S. (2010). Experimental study of mixed convection heat transfer in a vertical duct filled with metallic porous structures. International Journal of Thermal Sciences, 49(2), 340-348. 